\title{
RESEARCH
}

Open Access

\section{IGF-1 overexpression improves mesenchymal stem cell survival and promotes neurological recovery after spinal cord injury}

Kyan James Allahdadi, ${ }^{1,5}$, Thaís Alves de Santana ${ }^{1,3}$, Girlaine Café Santos ${ }^{1,3}$, Carine Machado Azevedo 1,2, Roberta Alves Mota ${ }^{2,3}$, Carolina Kymie Nonaka ${ }^{1,2,5}$, Daniela Nascimento Silva ${ }^{1,2,5}$, Clarissa Xavier Resende Valim, Cláudio Pereira Figueira², Washington Luis Conrado dos Santos ${ }^{2,3}$, Renan Fernandes do Espirito Santo ${ }^{2,3}$, Afrânio Ferreira Evangelista ${ }^{2}$, Cristiane Flora Villarreal ${ }^{2,3}$, Ricardo Ribeiro dos Santos ${ }^{1,4}$, Bruno Solano Freitas de Souza ${ }^{1,2,4,5}$ and Milena Botelho Pereira Soares ${ }^{1,2,4^{*}}$

\begin{abstract}
Background: Survival and therapeutic actions of bone marrow-derived mesenchymal stem cells (BMMSCs) can be limited by the hostile microenvironment present during acute spinal cord injury (SCl). Here, we investigated whether BMMSCs overexpressing insulin-like growth factor 1 (IGF-1), a cytokine involved in neural development and injury repair, improved the therapeutic effects of BMMSCs in SCl.

Methods: Using a SCl contusion model in C57BI/6 mice, we transplanted IGF-1 overexpressing or wild-type BMMSCs into the lesion site following $\mathrm{SCl}$ and evaluated cell survival, proliferation, immunomodulation, oxidative stress, myelination, and functional outcomes.

Results: BMMSC-IGF1 transplantation was associated with increased cell survival and recruitment of endogenous neural progenitor cells compared to BMMSC- or saline-treated controls. Modulation of gene expression of pro- and anti-inflammatory mediators was observed after BMMSC-IGF1 and compared to saline- and BMMSC-treated mice. Treatment with BMMSC-IGF1 restored spinal cord redox homeostasis by upregulating antioxidant defense genes. BMMSC-IGF1 protected against SCl-induced myelin loss, showing more compact myelin 28 days after SCl. Functional analyses demonstrated significant gains in BMS score and gait analysis in BMMSC-IGF1, compared to BMMSC or saline treatment.

Conclusions: Overexpression of IGF-1 in BMMSC resulted in increased cell survival, immunomodulation, myelination, and functional improvements, suggesting that IGF-1 facilitates the regenerative actions of BMMSC in acute $\mathrm{SCl}$.
\end{abstract}

Keywords: Spinal cord injury, Bone marrow-derived mesenchymal stem cells, IGF-1, Gene and cell therapy

\footnotetext{
* Correspondence: milena@bahia.fiocruz.br

'Center for Biotechnology and Cell Therapy, Hospital São Rafael, Salvador, BA, Brazil

${ }^{2}$ Gonçalo Moniz Institute, FIOCRUZ, Rua Waldemar Falcão, 121, Candeal,

Salvador, Bahia 40296-710, Brazil

Full list of author information is available at the end of the article
}

(c) The Author(s). 2019 Open Access This article is distributed under the terms of the Creative Commons Attribution 4.0 International License (http://creativecommons.org/licenses/by/4.0/), which permits unrestricted use, distribution, and reproduction in any medium, provided you give appropriate credit to the original author(s) and the source, provide a link to the Creative Commons license, and indicate if changes were made. The Creative Commons Public Domain Dedication waiver (http://creativecommons.org/publicdomain/zero/1.0/) applies to the data made available in this article, unless otherwise stated. 


\section{Background}

Spinal cord injury (SCI) affects millions of people across the globe, frequently leading to paralysis in a productive age, with a significant impact to the affected individual and family, as well as to the healthcare system [1]. Following the primary SCI event, the inflammatory response and oxidative stress can lead to augmented damage-secondary injury-to the tissue proximal to the injured site [2]. The loss of functional neurons and demyelination leads to impaired neural circuitry of the central nervous system (CNS), with limited spontaneous regenerative capacity [3]. Current treatment options are limited to supportive care and injury management, reinforcing the need for the development of novel treatment options that could limit secondary damage and stimulate the regeneration of the damaged spinal cord.

Stem cell therapy is a promising field that has been investigated as a therapeutic option for SCI [4]. While different types of adult, fetal-derived, or embryonic stem cells have been investigated, bone marrow-derived mesenchymal stem cells (BMMSCs) are an attractive option for such therapies, since the cells can be easily obtained and applied in autologous transplantation procedures. BMMSCs can promote SCI recovery through the immunomodulation [5], activation, and homing of endogenous stem/progenitor cells [6] and by the production of growth factors, neuroprotective cytokines, and chemokines [7, 8]. However, the effects of BMMSCs can be limited by poor survival or limited lifespan, following transplantation [5]. Genetic engineering of BMMSCs is a promising approach to improve cell survival and influence surround tissue via paracrine actions, through overexpression of specific growth factors of interest [9].

Insulin-like growth factor 1 (IGF-1) is a protein hormone that is produced and secreted by a variety of cells, including BMMSCs [10]. It is also an important growth factor that participates in the development of the central nervous system, as well as in recovery, following injury or pathological processes $[11,12]$. IGF-1 was previously reported to promote oligodendrocyte differentiation and survival during normal development [13], and IGF-1 overexpression leads to increased brain size and myelin content [14]. Moreover, IGF-1 acts as a potent antioxidant [15] and pro-survival [16] factor in the central nervous system. Therefore, the beneficial properties of IGF-1 could be an effective method in the treatment of SCI. We have recently generated and characterized a BMMSC line, genetically engineered to overexpress IGF-1 (BMMSC-IGF1) [9]. In the present study, we evaluated the therapeutic potential of BMMSC-IGF1 in a moderate contusion model of SCI in mice, by histopathological, immunological, and functional evaluation after treatment.

\section{Materials and methods}

Mesenchymal stem cell (BMMSC) culture

Wild-type BMMSCs were obtained from male GFP transgenic $\mathrm{C} 57 \mathrm{Bl} / 6$ mice. A genetically modified BMMSC line with stable overexpression of hIGF-1 (BMMSC-IGF1) was previously generated by the transduction with a lentiviral vector and characterized by our group [9]. BMMSCs were maintained in Dulbecco's modified Eagle's medium (DMEM), 10\% fetal bovine serum, and 1\% penicillin/streptomycin (all from Thermo Fisher Scientific, Waltham, MA, USA) in a humidified incubator at $37^{\circ} \mathrm{C}$ and atmosphere with $5 \% \mathrm{CO}_{2}$, under medium replacement every 3 days for expansion.

\section{Animals and surgical procedures for laminectomy and spinal cord injury}

C57Bl/6 female mice, 8-12 weeks old, were used throughout this study. Animals were raised and maintained at the animal facility of the Center for Biotechnology and Cell Therapy, Hospital São Rafael (Salvador, Brazil), with access to food and water ad libitum. The use of animals and experimental protocols were approved by the local Ethics Committee, which follows NIH guidelines (Hospital São Rafael, 02/12).

For spinal cord injury (SCI) induction, mice were anesthetized using ketamine $(80-100 \mathrm{mg} / \mathrm{kg}$ IP; Cristalia, Itapira, Brazil) and xylazine $(10-12.5 \mathrm{mg} / \mathrm{kg}$ IP, Rhobifarma, Hortolândia, Brazil), after which they were subjected to a laminectomy surgery, followed by contusive SCI. This involved identification of the tenth thoracic (T10) vertebra based on anatomical landmarks, followed by a dorsal laminectomy of T10. Following the removal of the T10 lamina, a moderate contusion injury $(\sim 70$ kdyn) was applied to the spinal cord using the Infinite Horizon Impactor (Precision Systems and Instrumentation, Fairfax Station, VA, USA). After SCI, $3 \mu$ of saline, BMMSCs $\left(1 \times 10^{6}\right.$ cells $)$, or BMMSC-IGF1 $\left(1 \times 10^{6}\right.$ cells $)$ were injected (Hamilton Syringe \#705) directly into the SCI epicenter, positioned with the use of a stereotaxic instrument (Kopf Instruments, Tujunga, CA, USA), at a flow rate of $1 \mu \mathrm{l} / \mathrm{min}$ (Harvard Apparatus Pump11 Elite). The muscle and skin were closed using 5-0 ethilon sutures (Ethicon-Johnson \& Johnson, Somerville, NJ, USA). Bladders were checked twice daily and manually voided when necessary, for the duration of the experiment.

\section{Functional recovery assessment}

Hind limb locomotor recovery was assessed on days 1 , 7, 14, 21, and 28 post-SCI, using the Basso Mouse Scale (BMS), an evaluation specifically designed for mouse models of contusive SCI [17]. Each scoring day, two blinded investigators, that were trained and experienced in BMS evaluations, performed the assessment on 
randomly selected mice in an open field during a 5-min period. A 70-kdyne contusive SCI normally results in immediate paraplegia in mice, demonstrating a nearly complete or complete loss of hind limb movement at 1 day after injury.

Additional functional analysis was performed using DigiGait, an undermount video recording and gait analysis system (DigiGait, Mouse Specifics, Inc. Framingham, MA, USA). Mice with SCI were conditioned to the DigiGait system, daily for 1 week, before actual experiments were conducted.

\section{Immunohistochemistry and histology}

Mice were terminally anesthetized and perfused with saline, then fixed with $4 \%$ paraformaldehyde (PFA) in PBS. The spinal cord was removed from the body, maintained overnight in $4 \%$ PFA $\left(4{ }^{\circ} \mathrm{C}\right)$ then cryoprotected overnight in 30\% sucrose in PBS. The next day, the spinal cord was trimmed down to the injured portion $(5 \mathrm{~mm}$ of total length) and either (1) embedded in Tissue-Tek, frozen and maintained at $-80^{\circ} \mathrm{C}$, then sectioned at $10 \mu \mathrm{m}$ or (2) fixed in $10 \%$ formalin, paraffin embedded and sectioned at $4 \mu \mathrm{m}$.

In frozen spinal cord sections, the following primary antibodies or dye were used: GFP, Ki-67, and cleaved caspase-3. Frozen sections were incubated in primary antibody solution containing chicken anti-GFP (1:800, Life Technologies, Carlsbad, CA, USA) and rabbit anti-mouse Ki-67 (1:800, Thermo Fisher Scientific, Waltham, MA, EUA) or rabbit anti-mouse cleaved caspase-3 (1:400, Cell Signaling, Danvers, MA, USA), diluted in PBS/BSA 1\%. After overnight $4{ }^{\circ} \mathrm{C}$ incubation, the sections were washed two times for $5 \mathrm{~min}$ in PBS Tween $0.05 \%$ and repeated in the same manner with PBS. The fluoromyelin staining was performed according to the manufacturer's protocol (FluoroMyelin green, Invitrogen, Carlsbad, CA, USA). Cryosections were fixed in paraformaldehyde 4\% (Electron Microscopy Sciences, Hatfield, PA, USA) for $15 \mathrm{~min}$, and sections were then permeabilized in Triton X-100 $0.1 \%$ for $10 \mathrm{~min}$. Non-specific protein binding was blocked by incubating the sections in PBS/BSA 5\% for $1 \mathrm{~h}$. Sections were then incubated with secondary antibody donkey anti-rabbit IgG Alexa Fluor 568 conjugated (1:1000, Molecular Probes, Carlsbad, CA, USA) and donkey anti-chicken IgG Alexa Fluor 488 conjugated (1:600, Molecular Probes, Carlsbad, CA, USA) for $1 \mathrm{~h}$ at room temperature. Nuclei were counterstained with 4,6-diamidino-2-phenylindole (DAPI) (Vector Labs, Burlingame, CA, USA).

Paraffin-embedded sections were performed following standard histological methods, briefly detailed below. Following deparaffinization, rehydration, and heat-induced antigen retrieval, the Mouse-on-mom kit
(M.O.M kit, Vector Labs, Burlingame, CA, USA) was used to stain with the following primary antibodies: goat anti-mouse Iba-1 (1:1000, Abcam, Cambridge, UK), mouse anti-PCNA (1:200, Agilent, Santa Clara, CA, USA), rabbit anti-mouse APC (1:200, Santa Cruz, Dallas, TX, USA), rabbit anti-mouse GFAP (1:1000, Agilent, Santa Clara, CA, USA), or rabbit anti-mouse doublecortin (1:200, Abcam, Cambridge, UK). Sections were then incubated with secondary antibody donkey anti-rabbit IgG Alexa Fluor 568 conjugated (1:1000, Molecular Probes, Carlsbad, CA, USA) and streptavidin Alexa Fluor 488 conjugated (1:800, Molecular Probes, Carlsbad, CA, USA) for $1 \mathrm{~h}$ at room temperature. Nuclei were counterstained with 4,6-diamidino-2-phenylindole (DAPI) (Vector Labs, Burlingame, CA, USA).

The presence of fluorescent cells was determined by observation using a confocal laser scanning microscope A1R (Nikon, Tokyo, Japan) and processed using Image-Pro Plus version 7.01 (MediaCybernetics, Rockville, MD, USA). Lesion volume measurement was based on GFAP staining, which concentrated on the border of the injured region, combined with fluoromyelin staining of the remaining tissue in the section. Therefore, lesion volume was determined based on the ratio of the injured region (void of stained myelin and marked by GFAP) and uninjured region (area marked by fluoromyelin).

\section{Estimation of nitrite and lipid peroxidation}

At the end of the experimental period, spinal cords were collected. Injured spinal cord segments (T9-T10) were rinsed with ice-cold saline $(0.9 \%$ sodium chloride) and homogenized in chilled phosphate buffer ( $\mathrm{pH}$ 7.4). Thus, the homogenate obtained was used to assay lipid peroxidation and nitrite estimations. The malondialdehyde (MDA) content, a marker of lipid peroxidation, was assayed in the form of thiobarbituric acid-reactive substances, as previously described [18]. Briefly, $0.5 \mathrm{ml}$ of homogenate and $0.5 \mathrm{ml}$ of Tris- $\mathrm{HCl}$ were incubated at $37^{\circ} \mathrm{C}$ for $2 \mathrm{~h}$. After incubation, $1 \mathrm{ml}$ of $10 \%$ trichloroacetic acid was added and centrifuged at $1000 \mathrm{~g}$ for $10 \mathrm{~min}$. For every $1 \mathrm{ml}$ of supernatant, $1 \mathrm{ml}$ of $0.67 \%$ thiobarbituric acid was added and the tubes were kept in boiling water for $10 \mathrm{~min}$. After cooling, $1 \mathrm{ml}$ of double distilled water was added and absorbance was measured at $532 \mathrm{~nm}$. Thiobarbituric acid-reactive substances were quantified using an extinction coefficient of $1.56 \times 10^{5}$ $\mathrm{M}^{-1} \mathrm{~cm}^{-1}$ and were expressed as nmol of malondialdehyde per mg protein. Nitrite was estimated in the spinal cord homogenate using the Griess reagent and served as an indicator of nitric oxide production. A quantity of $500 \mu \mathrm{L}$ of Griess reagent (1:1 solution of $1 \%$ sulphanilamide in $5 \%$ phosphoric acid and $0.1 \%$ naphthylamine diamine dihydrochloric acid in water) was added to $100 \mu \mathrm{L}$ of homogenate and absorbance was 
measured at $546 \mathrm{~nm}$. Nitrite concentration $(\mu \mathrm{g} / \mathrm{ml})$ was calculated using a standard curve for sodium nitrite.

\section{RT-qPCR}

Total RNA has been extracted using TRIZOL (Thermo Fisher Scientific, Waltham, MA, USA) following the manufacturer's instruction. RNA integrity was assayed by $1 \%$ agarose electrophoresis, and purity was measured photometrically using the NanoDrop ${ }^{\text {tw }} 1000$ (Thermo Fisher Scientific, Waltham, MA, USA). RNA samples ( $1 \mu \mathrm{g}$ per sample) were converted to cDNA using High-Capacity cDNA Reverse Transcription Kit (Thermo Fisher Scientific, Waltham, MA, USA). In order to quantify mRNA expression, Mrc1 (Mm00485148_m1), Sod1 (Mm01344233_g1), Cat (Mm00437992_m1), Gpx3 (Mm00492427_m1), and Nfe2l2 (Mm00477784_m1) Taqman Master Mix and Taq$\operatorname{man}^{\text {Tx }}$ probes were used in a final volume of $10 \mu \mathrm{L}$, following the manufacturer's instruction (all from Thermo Fisher Scientific, Waltham, MA, USA). All RT-qPCR data was normalized with Gapdh and Hprt. PCR amplification was performed in an ABI7500 Real-Time PCR System (Applied Biosystems, Foster City, CA, USA) under standard thermal cycling conditions. The threshold cycle method of comparative PCR was used to analyze the results [19]. Data was analyzed using GraphPad software version 6.

\section{Transmission electron microscopy}

Twenty-eight days post-lesion, 12 animals (BMMSC-IGF1, $n=3$; BMMSCs, $n=3$; saline, $n=3$; uninjured control, $n=3$ ) were terminally anesthetized and perfused with $4 \%$ paraformaldehyde and $0.25 \%$ glutaraldehyde (Sigma-Aldrich, St. Louis, MO, USA) in $0.1 \mathrm{M}$ sodium cacodylate buffer. Spinal cords were collected and fixed at $4{ }^{\circ} \mathrm{C}$ for $24 \mathrm{~h}$ in a solution of $2 \%$ paraformaldehyde and $2.5 \%$ glutaraldehyde in $0.1 \mathrm{M}$ sodium cacodylate buffer. Following fixation, $1 \mathrm{~mm}$ injured spinal cord segments (lesion site) were removed and maintained in the fresh fixing solution (above) for $72 \mathrm{~h}$. Segments were then washed with $0.1 \mathrm{M}$ sodium cacodylate buffer and post-fixed in osmium tetroxide (Electron Microscopy Sciences Inc., Hatfield, PA, USA) 1\% for $1 \mathrm{~h}$. Segments were dehydration by using a graded series of acetone solutions (from 30 to 100\%) before embedding the samples in epoxy resin Polybed812 (Electron Microscopy Sciences Inc., Hatfield, PA, USA). Ultrathin sections were obtained using EM UC7 ultramicrotome (Leica Microsystems, Wetzlar, Germany) and contrasted with uranyl acetate and lead citrate. The sections were analyzed by transmission electron microscope JEM1230 (JEOL, Tokyo, Japan) at $80 \mathrm{kV}$.

For the analysis of histopathological alterations, 10 images were randomly taken from each animal and analyzed by three experienced investigators in order to visualize the presence of collagen fibers, degeneration vacuoles, and myelinated and demyelinated axons, for quantitative analysis. Magnification for all images was set at $\times 5000$ using Fiji software version 1.51. Additionally, three images from each animal were selected to measure axon diameter (inner diameter of the axon), fiber diameter (inner diameter of the axon plus myelin sheath), myelin thickness, and g-ratio (axon diameter/fiber diameter). For this analysis, images with a greater number of myelinated axons from each animal were selected.

\section{Statistical analyses}

Behavioral data were analyzed using the two-way ANOVA (group and time) followed by Bonferroni's multiple comparisons. Remaining data were analyzed using Student's $t$ test or one-way ANOVA followed by Tukey or Newman-Keuls multiple comparison tests. All data were analyzed using the GraphPad Prism v.5.0 software (GraphPad Inc., San Diego, CA, USA). Differences were considered statistically significant for $P$ values $<0.05$.

\section{Results}

IGF-1 expression increases survival of transplanted BMMSCs and activation of endogenous progenitors in acute $\mathrm{SCl}$

After induction of SCI, mice were injected intralesionally with BMMSCs, BMMSC-IGF1, or saline, as shown in Additional file 1: Figure S1. First, we evaluated the presence of transplanted BMMSCs and BMMSC-IGF1 in the injured spinal cord, by tracking $\mathrm{GFP}^{+}$cells. The number of $\mathrm{GFP}^{+}$cells detected in the SCI epicenter 5 days post-injury was higher in mice transplanted with BMMSC-IGF1 than with wild-type BMMSCs (Fig. 1a, b). This was confirmed by GFP gene expression analysis by RT-qPCR, which demonstrated increased GFP gene expression in the spinal cord of mice transplanted with BMMSC-IGF1, when compared to those receiving wild-type BMMSCs (Fig. 1c).

The higher numbers of $\mathrm{GFP}^{+}$cells in the spinal cord of BMMSC-IGF1 mice could be the result of increased cell proliferation or pro-survival actions induced by IGF-1. Therefore, we evaluated if IGF-1 overexpression induces the proliferation of donor and/or recipient cells in the spinal cord, by analyzing the proliferation marker Ki67. Proliferating cells were mostly recipient cells, since $\mathrm{GFP}^{+} \mathrm{Ki}^{+} 7^{+}$cells were rarely observed (Fig. 1d, e) and represented $\sim 2.2 \%$ of the number of proliferating cells in the spinal cord in the BMMSC-IGF1-treated group. The number of $\mathrm{GFP}^{+} \mathrm{Ki}^{+} 7^{+}$cells was similar to BMMSCand BMMSC-IGF1-treated mice (data not shown). In order to evaluate if IGF-1 expression could increase cell survival by inhibiting apoptosis, we performed immunostaining for cleaved caspase-3 and quantified the number of cells undergoing apoptosis, 2 and 5 days post-SCI (Fig. 1f). We detected a higher number of Casp3 ${ }^{+}$cells 


\section{BMMSC}
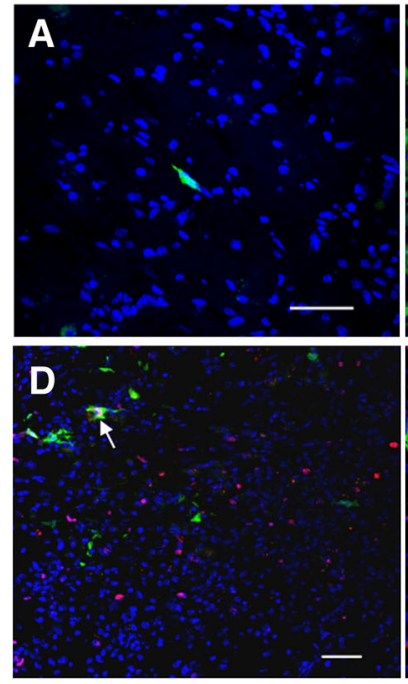

BMMSC-IGF1
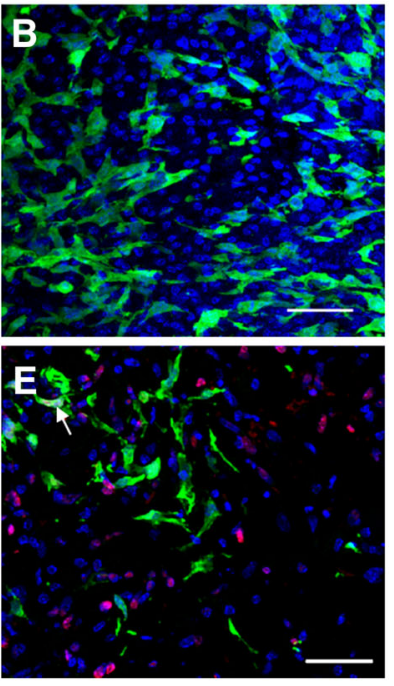
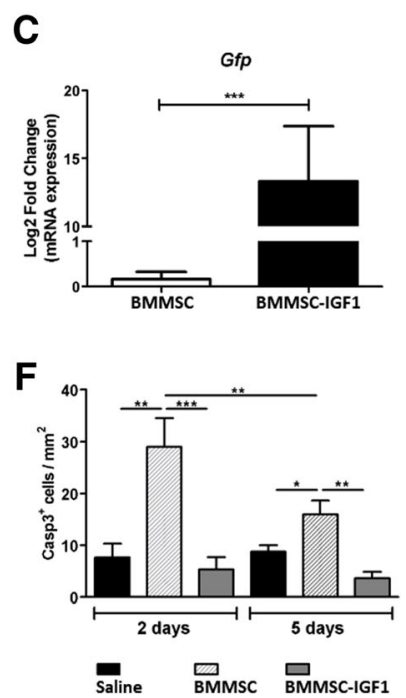

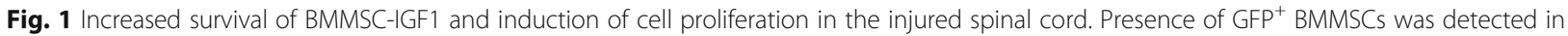
spinal cord sections of mice transplanted with wild-type BMMSCs (a) or BMMSC-IGF1 (b), visualized in green by confocal microscopy, 5 days after spinal cord injury and cell transplantation. Nuclei were stained with DAPI (blue). Scale bars $=50 \mu \mathrm{m}$. c Quantification of GFP mRNA in the injured spinal cord segments, isolated at 5 days post-injury and transplant, measured by qRT-PCR. Confocal microscopy of injured mouse spinal cords, 5 days post-injury and transplanted with wild-type BMMSC (d) or BMMSC-IGF1 (e), immunostained for the proliferation marker Ki-67 (red) and nuclei stained with DAPI (blue). Scale bars $=200 \mu \mathrm{m}$. $\mathbf{f}$ Quantification of Casp3 ${ }^{+}$-labeled cells in spinal cord sections. Values represent mean \pm SEM. ${ }^{*} P<0.05 ;{ }^{* *} P<0.01 ;{ }^{* *} P<0.001$

in the group treated with wild-type BMMSCs in both time points, with an increased number of $\mathrm{Casp}^{+}$cells 2 and 5 days after SCI-cell transplantation, in the BMMSC-treated group (Fig. 1f).

Proliferating cells $\left(\mathrm{Ki} 67^{+}\right)$were mainly located in the central canal, proximal to the injury area, 2 days after SCI (Fig. 2). Increased proliferation of central canal ependymal cells was observed in mice treated with either BMMSCs or BMMSC-IGF1, when compared to saline-treated and uninjured mice (Fig. 2a-d). Transplanted cells were found proximally to cells proliferating in the central canal (Fig. 2e). At 5 days post-injury, proliferation of central canal cells was reduced and we observed an increased number of proliferating cells surrounding the injury area, which was greater in BMMSC-IGF1-treated mice (Fig. 2f).

Next, we investigated whether BMMSC-IGF1 transplantation was associated with activation of endogenous progenitors. We stained for immature neurons/progenitors (DCX) and observed a greater number of $\mathrm{DCX}^{+}$cells in spinal cords from injured mice transplanted with BMMSC-IGF1 when compared to uninjured, saline-treated, and BMMSCs-treated, 5 days post-injury (Fig. $3 \mathrm{a}-\mathrm{d}$ ). $\mathrm{DCX}^{+}$ cells were not co-stained with a proliferation marker (Fig. 3b) and were mainly located in the area surrounding the injury (Fig. 3c). Additionally, BMMSC-IGF1 treatment resulted in increased staining of macrophage/microglia marker (IBA1, Fig. 3e). We also evaluated the expression of markers for oligodendrocyte differentiation-MBP, Olig1, Olig2, and Nkx2.2-by RT-qPCR of the spinal cord tissue (Fig. 3f-i). While MBP gene expression was similar between the groups, $\mathrm{Nkx2}$.2 was increased in all injured spinal cords, and Olig1 and Olig2 levels of expression were increased in BMMSC and BMMSC-IGF1 groups.

\section{Modulation of inflammatory cytokines and oxidative stress by BMMSC-IGF1}

Following the observation of increased Iba1 staining after therapy with BMMSC-IGF1, we evaluated the expression of macrophage/microglia polarization markers, NOS2 (type I activation marker, Inos) (Fig. 4a), as well as type II activation markers Arg1 (Fig. 4b), and Chi3L3 (Fig. 4c), which were found to be increased in BMMSC-IGF1-treated mice, when compared to vehicle or wild-type BMMSCs-treated mice. Mrc1 was increased following treatment with BMMSC and BMMSC-IGF1, when compared to saline (Fig. 4d). Gene expression analysis of factors related to anti-oxidant response showed increased expression of Nfe2L2 (Fig. 4e), Cat (Fig. 4f), and Gpx3 (Fig. 4g) in mice treated with BMMSC-IGF1, when compared to wild-type BMMSC or vehicle treatment. Based on this, we investigated the production of oxidative stress metabolites in the injured spinal cord. MDA content, an indicator of lipid peroxidation, was significantly reduced in the BMMSC-IGF1 

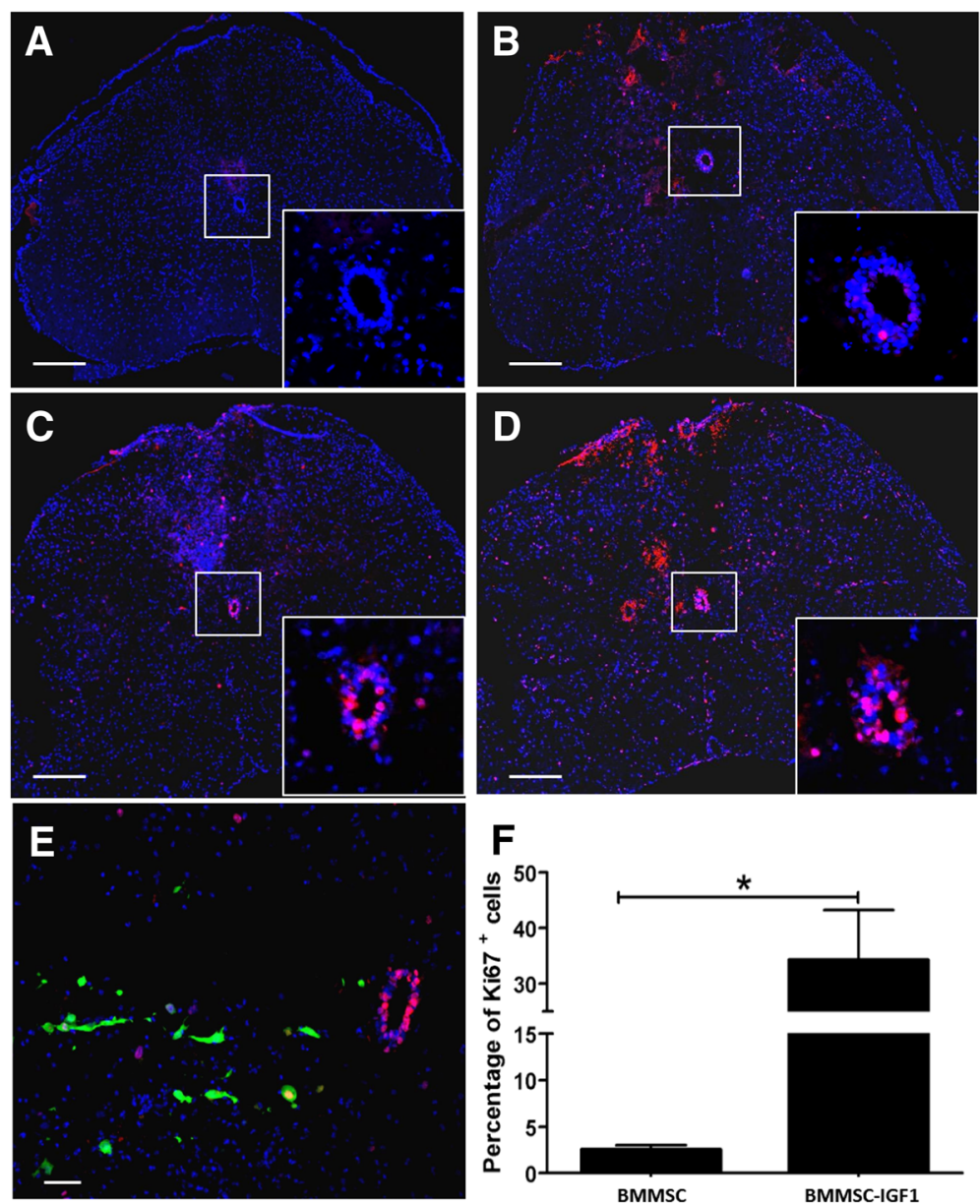

Fig. 2 Cellular proliferation in injured mouse spinal cords following BMMSC-IGF transplantation. Spinal cord segments from a uninjured mouse and SCI mice treated with $\mathbf{b}$ saline, $\mathbf{c}$ BMMSCs and $\mathbf{d}$, e BMMSC-IGF1, observed by confocal microscopy, 2 days following spinal cord injury and cell transplantation, immunostained for Ki-67. Scale bars $=200 \mu \mathrm{m}(\mathbf{a}-\mathbf{d})$; scale bar $=50 \mu \mathrm{m}(\mathbf{e})$. Central canal (highlighted/insert, a-d). $\mathbf{f}$ Quantitative percentage of $\mathrm{Ki}-67^{+}$in the spinal cord 5 days post-injury. Values represent mean \pm SEM. ${ }^{*} P<0.05 ;{ }^{* *} P<0.01$; ${ }^{* * *} P<0.001$

group when compared to BMMSC and saline samples (Fig. 4h). Similarly, nitrite concentration was significantly reduced in the BMMSC-IGF1-treated group when compared to saline, but not when compared to BMMSC-treated mice (Fig. 4i).

\section{Functional improvements in $\mathrm{SCl}$ mice treated with BMMSC-IGF1}

After the conclusion of short-term analyses, we performed experiments to evaluate functional recovery during the 4 weeks following SCI to investigate whether BMMSC-IGF1 therapy resulted in locomotion improvement in SCI mice. First, we applied the Basso Mouse Scale (BMS) score to evaluate the progressive gains in gait, weight bearing, and coordination [17]. BMS scoring analysis was initiated 1 week after SCI and therapy and was repeated weekly over the course of 28 days. Significant gains in BMS were observed in SCI mice treated with BMMSC-IGF1 beginning at week 2 and continued until the conclusion at week 4, compared to BMMSC-treated and vehicle (saline)-treated SCI mice (Fig. 5a). No significant difference was observed between BMMSC- and saline-treated SCI mice. Body weight was simultaneously measured, and no difference between groups was observed post-injury and during the recovery period (Fig. 5b).

Gait analysis was performed using the DigiGait system, which was evaluated 2, 3, and 4 weeks after SCI and treatment. Gait symmetry is evaluated to determine the ratio of forelimb-to-hindlimb stepping, which is approximately 1.0 in uninjured mice. Gait symmetry in BMMSC-IGF1 SCI mice was significantly higher than uninjured mice at week 2; however, no difference was measured during weeks 3 and 4, while saline-treated SCI mice were significantly different from uninjured mice at all time points (Fig. 5c). Various aspects of hindlimb stride were analyzed, including stride length (Fig. 5d), stride duration (Fig. 5e), and stride frequency (Fig. 5f). Significant differences between uninjured and SCI BMMSC-IGF1 mice were 


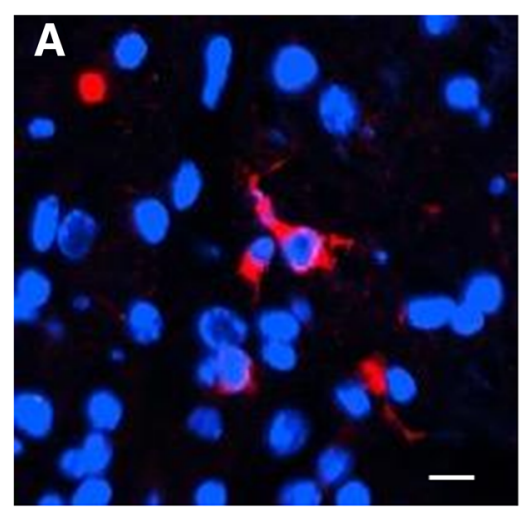

D

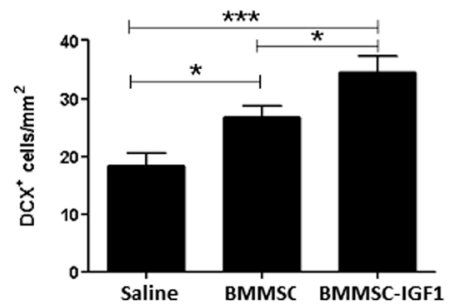

G

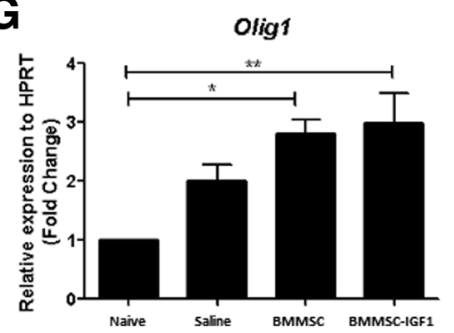

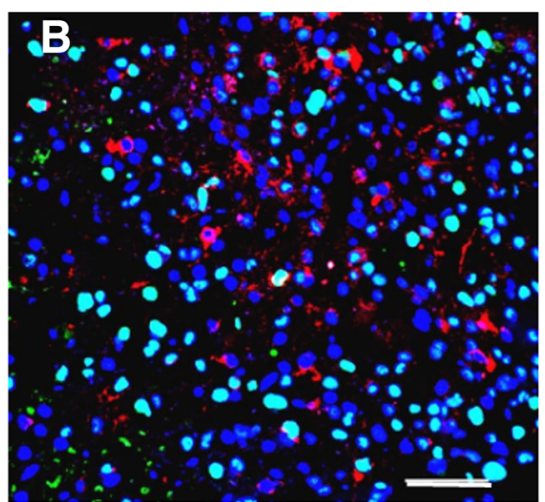

E

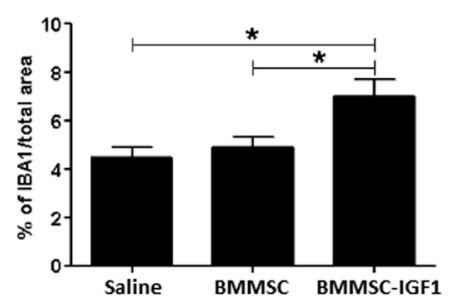

H

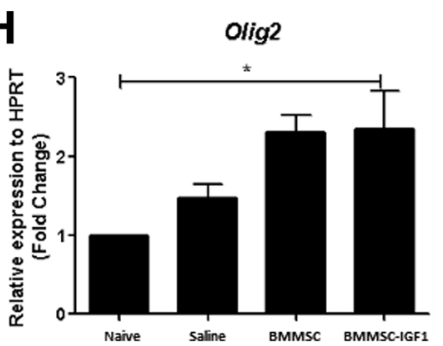

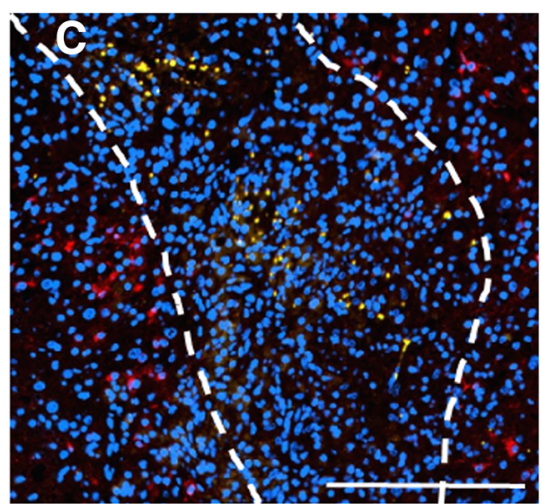

$\mathbf{F}$
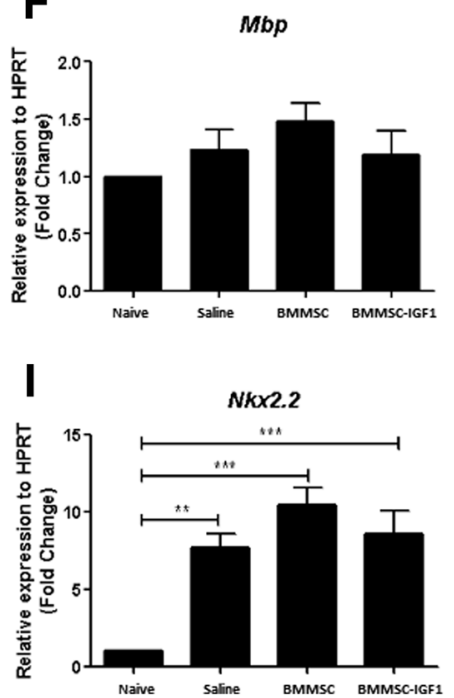

Fig. $3 \mathrm{SCI}$ mice treated with BMMSC-IGF1 demonstrate elevated progenitor cell presence, 5 days following SCI and transplant. Injured spinal cord section from BMMSC-IGF1-treated mouse immunostained for a DCX (red; scale bar = $10 \mu \mathrm{m}$ ), $\mathbf{b}$ double immunostained for DCX and PCNA (green; scale bar $=10 \mu \mathrm{m}$ ), and $\mathbf{c}$ detailed region with DCX (red; scale bar $=100 \mu \mathrm{m}$ ). Quantitative analysis of $\mathbf{d}$ DCX-positive cells and $\mathbf{e}$ percentage of IBA1 cells from injured spinal cords. RT-qPCR analysis of expression of $\mathbf{f} \mathbf{M b p}, \mathbf{g}$ Olig1, $\mathbf{h}$ Olig2, and i NKx2.2, genes associated with oligodendrocyte progenitor cells differentiation. Values represent mean $\pm \mathrm{SEM}$. ${ }^{*} P<0.05 ;{ }^{* *} P<0.01$; ${ }^{* * *} P<0.001$

measured at 2 weeks, in all parameters (Fig. $5 \mathrm{c}-\mathrm{f}$ ); however, starting at week 3 and continuing to week 4 , BMMSC-IGF1 levels were similar to uninjured levels. Saline-treated SCI mice demonstrated improvements in stride length and duration by week 4 (Fig. $5 \mathrm{~d}$, e) but had no significant gains in stride frequency (Fig. 5f). Representative images of an uninjured mouse and SCI mice after 4 weeks of treatment with saline, BMMSC, and IGF1, demonstrating hindlimb positioning and gains measured in DigiGait analysis (Additional file 2: Figure S2 and Supplemental Videos 1-4).

\section{BMMSC-IGF1 treatment results in increased remyelination in $\mathrm{SCl}$ mice}

Lesion volume of $\mathrm{SCI}$ was assessed at the conclusion of the study, 28 days following SCI and treatment. Spinal cord sections were stained for GFAP, in order to evaluate and compare lesion volume between the groups. There was no statistical difference between saline, BMMSC, or BMMSC-IGF1 at the injury epicenter, rostrally or caudally (300 $\mu \mathrm{m}$ from the epicenter, in $100 \mu \mathrm{m}$ intervals) (Figs. 6a, b).

Myelination was evaluated by fluoromyelin staining (Figs. 6c-e). Similar myelin staining was detected in all groups in the epicenter; however, fluoromyelin-positive staining was significantly higher in SCI-BMMSC-IGF1 mice in slices $300 \mu \mathrm{m}$ from the epicenter, compared to BMMSC and saline-treated (Fig. 6f).

In order to confirm the finding of increased myelination in the BMMSC-IGF1 group 28 days post-SCI, we performed transmission electron microscopy to assess ultrastructural morphology in the spinal cord from uninjured, saline-treated, BMMSCs-treated, and BMMSC-IGF1-treated mice. Saline-treated spinal cords presented more dense collagen bundles (Fig. 7b), higher number of degeneration vacuoles (Fig. 7f), and higher number of degenerating axons with myelin sheath collapse (Fig. 7j) when compared to 


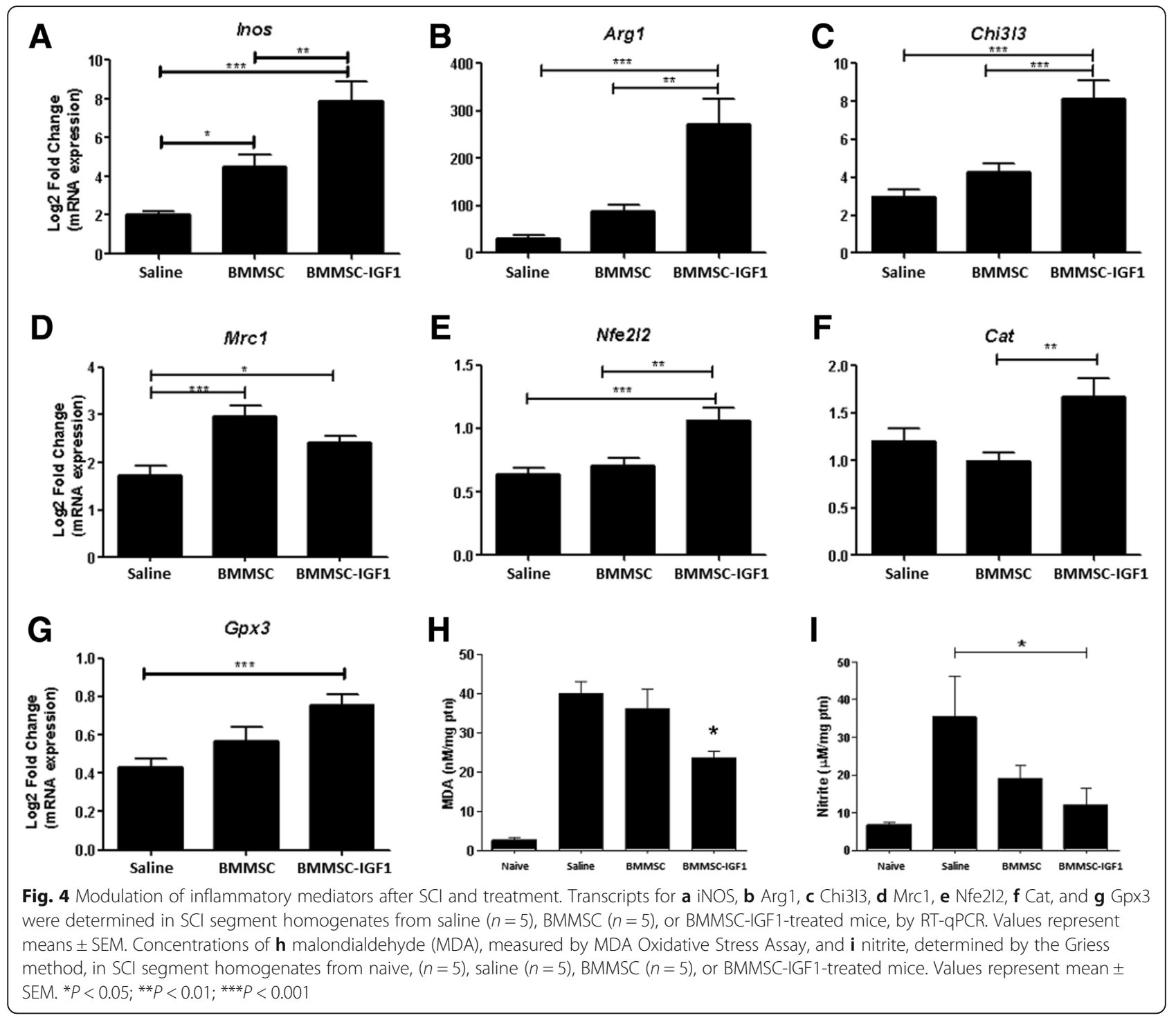

BMMSC(Fig. 7c, g, and k) or BMMSC-IGF1-treated animals (Fig. 7d, h, and l). Conversely, nerve axons-containing preserved myelin sheaths (Fig. 7k, l) and loosely organized, thin collagen fibers (Fig. 7c, d) were more frequently observed in BMMSC- and BMMSC-IGF1-treated animals (Table 1).

The impact of trauma on axonal myelination revealed a greater demyelinated axon profile in saline-treated mice, while more myelinated axons were observed in BMMSC-and BMMSC-IGF1-treated groups (Fig. 7; Table 1). The pattern of myelin and axons of BMMSC-IGF1 (Fig. 7d) was similar to that observed in uninjured mouse spinal cords (Fig. 7a), with the presence of compact myelin and fewer demyelinated axons.

We also observed a significant reduction in the total number of myelinated axons from spinal cords with saline treatment $(n=218)$ when compared to uninjured $(n=1193)$, BMMSC-IGF1 $(n=942)$, and BMMSC $(n=940)$. Linear regression of morphometrical analysis parameters demonstrated that BMMSC (Fig. 8c) and BMMSC-IGF1 (Fig. 8d) treated spinal cord lesions presented a similar profile to uninjured mice than saline-treated mice (Fig. 8a). Finally, analysis of g-ratio distribution by range (Fig. 8b) showed a significant difference between both BMMSCs-treated groups when compared to saline animals.

\section{Discussion}

In the present study, we demonstrated that IGF-1 overexpression increases the therapeutic potential of BMMSCs in a moderate contusion SCI mouse model treated during the acute injury phase. We observed that therapy with wild-type BMMSCs led to changes in different parameters evaluated, usually in lower magnitude than what was observed in mice treated with BMMSC-IGF1. However, functional gains were found to be statistically significant only for the group treated with BMMSC-IGF1. This could be the result of direct actions 

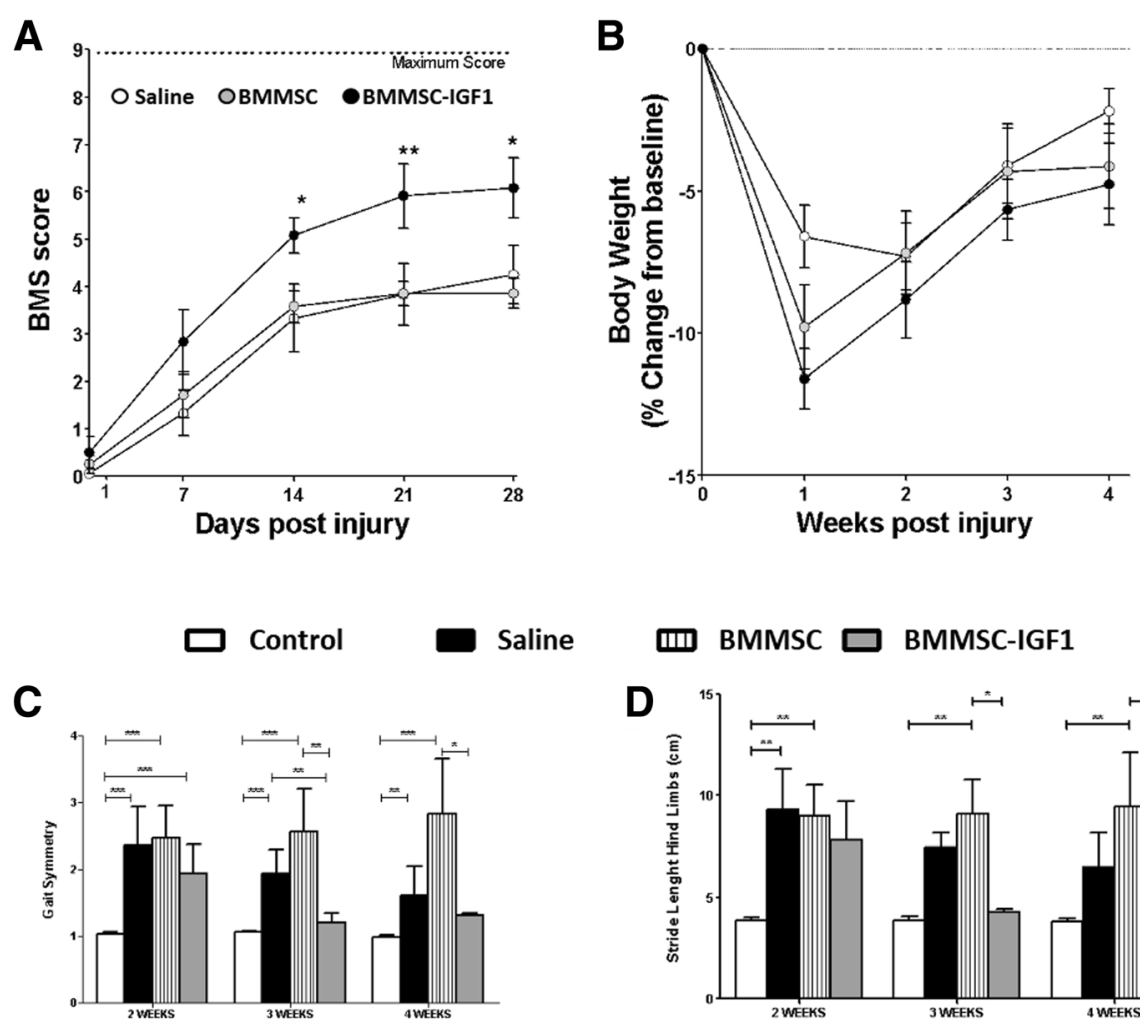

Saline 血 BMMSC $\square$ BMMSC-IGF1
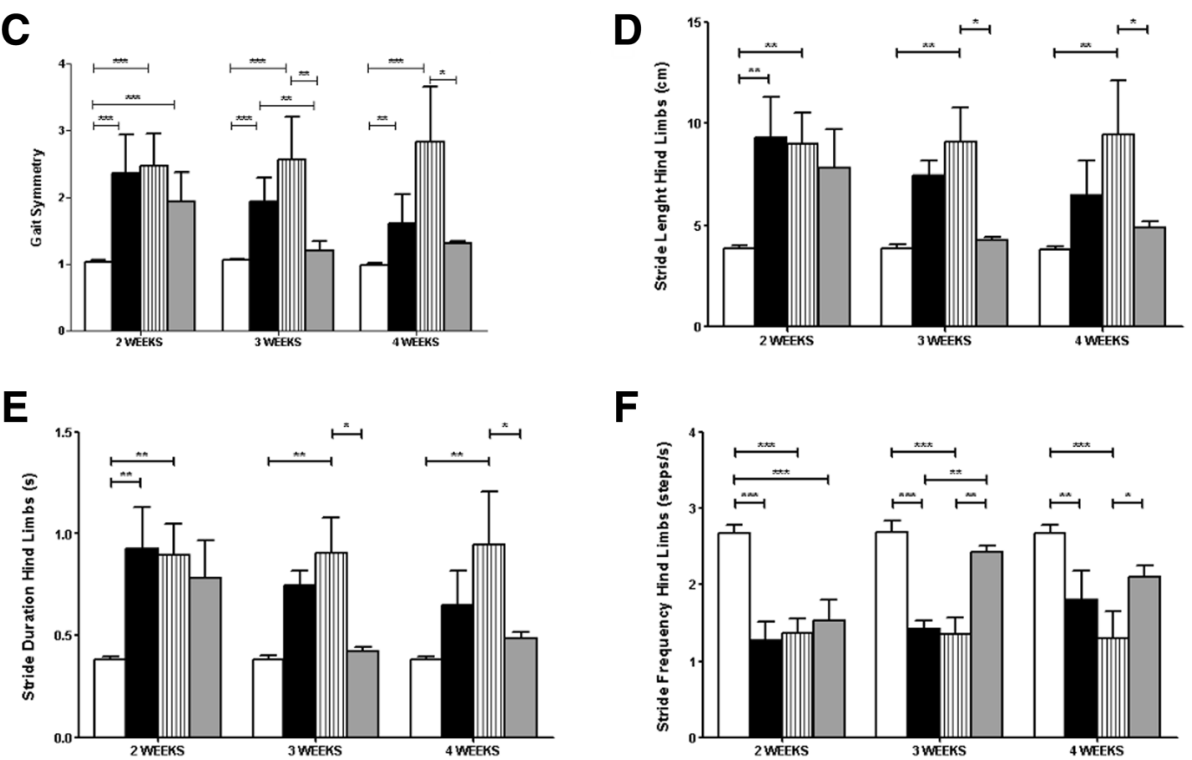

$\mathbf{F}$

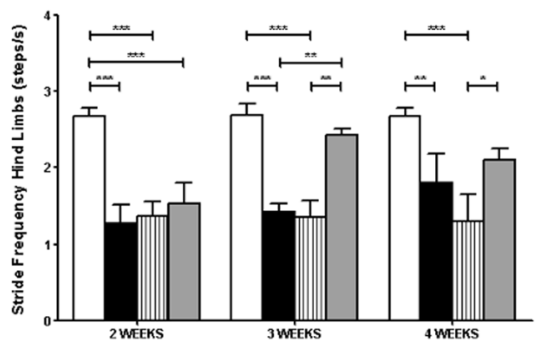

Fig. 5 Functional analysis following SCI and treatment. Functional analysis (a) of saline-, BMMSC-, and BMMSC-IGF1-treated mice, evaluated weekly from day 1 to 28 days using the Basso Mouse Score (BMS). Body weight (b) was assessed with BMS and is represented as percent change in body weight, based on weight prior to injury (baseline). DigiGait-derived functional measurements of $\mathbf{c}$ gait symmetry, $\mathbf{d}$ stride length, e stride duration, and $\mathbf{f}$ stride frequency were evaluated at weeks 2 , 3, and 4. Values represent mean \pm SEM. ${ }^{*} P<0.05$; ${ }^{*} P<0.01$; and ${ }^{* * *} P<0.001$

of locally released IGF-1, a growth factor known to participate in the development of the central nervous system as well as in neurogenesis and repair following injury $[20,21]$. It is also possible that other intrinsic paracrine actions exerted by BMMSCs were sustained and even enhanced by the increased survival of BMMSC-IGF1 observed in the injured spinal cord.

The acute phase of SCI is characterized by an inflammatory response, which produces a hostile microenvironment during this period $[22,23]$. It has been demonstrated that BMMSCs have a very short life span after injection due to several factors, including inflammation and increased oxidative stress [24]. Also, after transplantation, BMMSCs are submitted to an environment of very low glucose levels, near-anoxia, and fail to adapt their metabolism in these conditions, which leads to a rapid depletion of energy reserves and poor survival [5]. In the present study, we demonstrated that IGF-1 overexpression in BMMSCs increases cell survival rate after transplantation to the injured spinal cord, which can be explained by the known pro-survival and anti-apoptotic actions of IGF-1 [25-28]. It is also possible that IGF-1 could act by altering the metabolism of BMMSCs by conferring higher energetic reserves.

Additionally, we observed an increased number of proliferating cells in the spinal cord after treatment with BMMSC-IGF1 and increased number of $\mathrm{Iba}^{+}$in the BMMSC-IGF1 group. IGF-1 acts as a mitogen for microglia/ 

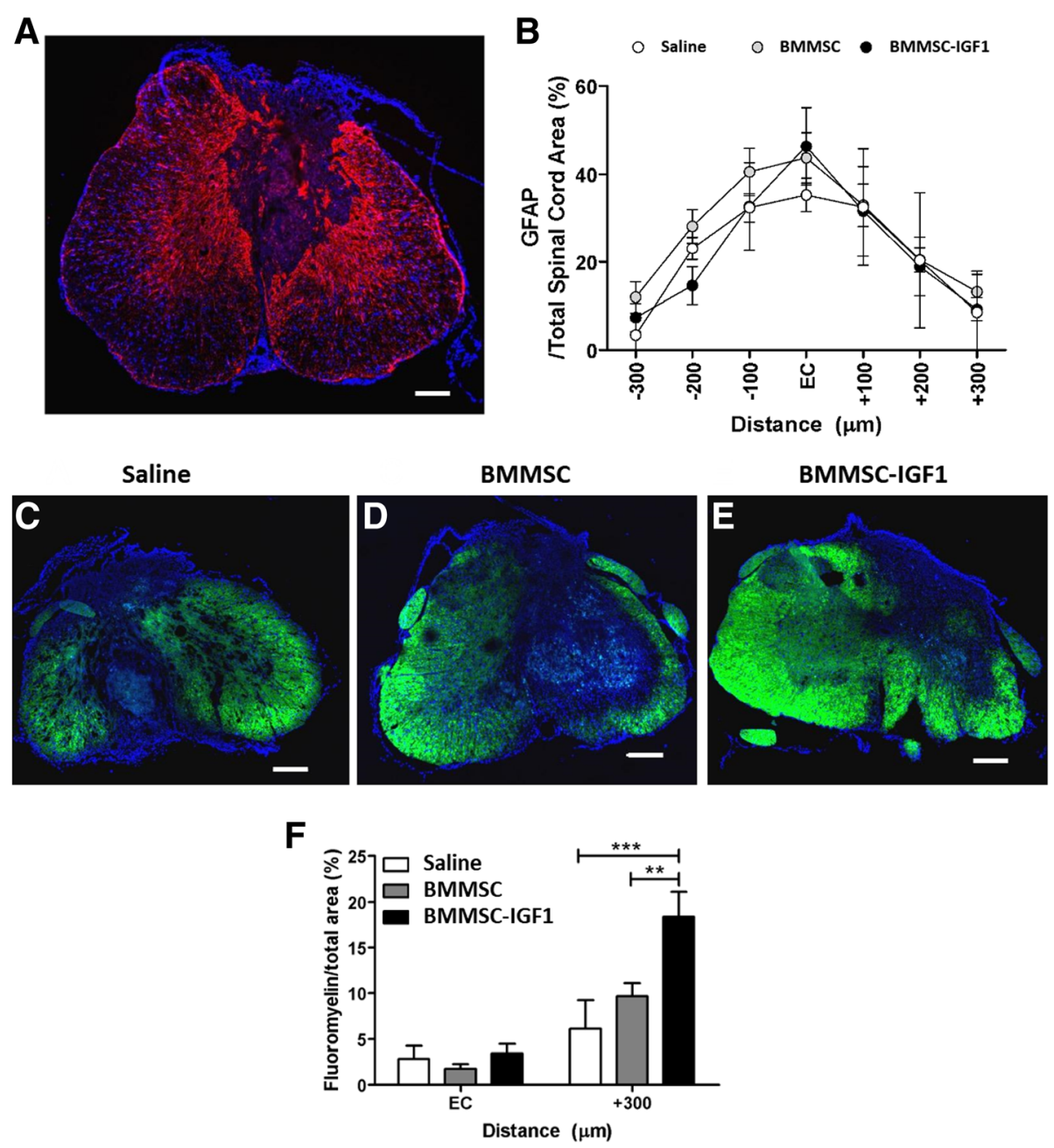

Fig. 6 Lesion volume and myelination 4 weeks following $\mathrm{SCl}$ and treatment. Lesion volume (a) as measured by GFAP staining, which is concentrated around the lesion site, measured against total spinal cord area bilaterally from the epicenter (EC) of the injury. $\mathbf{b}$ Quantification of GFAP derived lesion volume. Myelination immunostaining with fluoromyelin was performed in saline (c), BMMSC (d), and BMMSC-IGF1 (e) treated $\mathrm{SCl}$ sections. Quantitative analysis (f) of fluoromyelin-labeled oligodendrocytes at the EC and $300 \mu \mathrm{m}$ caudally. Bars represent means \pm SEM of five mice/group. Values represent mean \pm SEM. ${ }^{*} P<0.05$ (BMMSC-IGF1: EC vs +300$),{ }^{\#} P<0.05$ (+ 300: BMMSC-IGF1 vs BMMSC)

macrophages in the central nervous system (CNS) [9]. Microglia play an important role in CNS inflammation, as well as in adult neurogenesis. Microglia activation can be detrimental to the survival of newly formed CNS neurons, due in part to the pathological microenvironment [20,21], but it may be also beneficial, supporting adult neurogenesis and myelination [29]. One such mechanism that microglia has been reported to act benevolently is by mediating an increase in IGF-1 levels, which was shown to lead to neurogenesis and cell proliferation $[21,30]$.

Increased numbers of $\mathrm{DCX}^{+}$cells were also observed in the group treated with BMMSC-IGF1, suggesting that transplantation of BMMSC-IGF1 recruited endogenous progenitor cells to the injury site. Previously, IGF-1 has been demonstrated to stimulate the production of stromal cell-derived factor (SDF-1) and SDF-1 signaling through CXCR4 leading to protection of neural progenitor cells against hypoxia [31] and is a crucial factor for neural progenitor cells stemness [32]. Additionally, the IGF-1 protein has been reported to promote differentiation by directly binding to IGF-1 receptors on neural stem cells [33]. These data suggest that BMMSC-IGF1 may support the recruitment and maintenance of neural progenitors to the spinal cord following injury, which may participate in the recovery after SCI.

The improved functional outcomes in SCI BMMSC-IGF1 mice appears to be significantly attributed to their effectiveness in minimizing the secondary injury damage to axons and oligodendrocytes, by reduction of oxidative stress. These spared CNS cells were better preserved, as observed by electron microscopy, especially at the g-ratio range of $0.7-0.8$, considered to be the optimal 


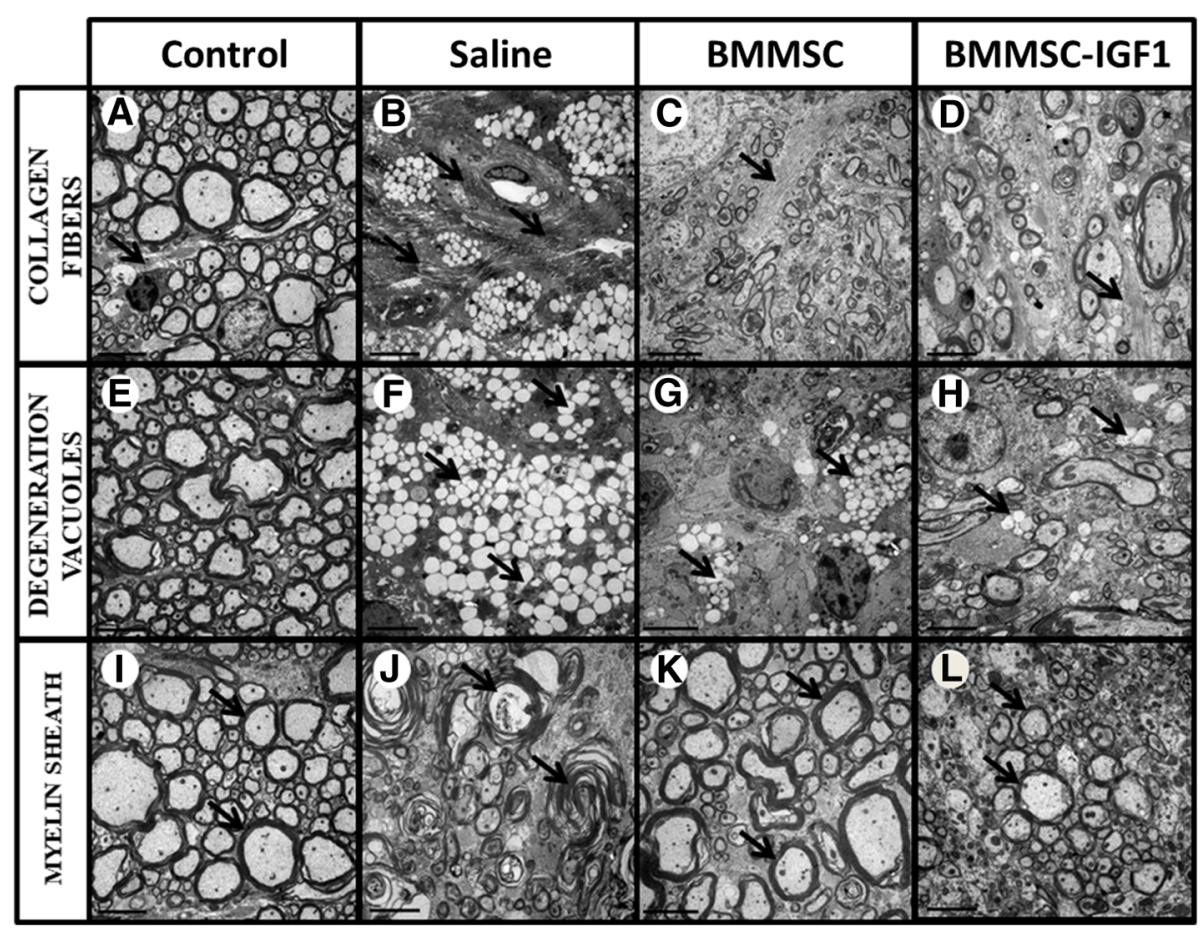

Fig. 7 Ultrastructural changes at the site of lesion in animals with SCI visualized by transmission electron microscopy. Representative images of spinal cord sections obtained from uninjured or SCl-mice admistered with saline, BMMCs or BMMC-IGF1 are shown. Morphological patterns of collagen fibers (a-d), degeneration vacuoles $(\mathbf{e}-\mathbf{h})$ and myelin sheath (i-I) were evaluated, as indicated by black arrows. Scale bar $=5 \mu \mathrm{m}$

value of myelinated fibers [34] and ultimately a more favorable functional recovery. We speculate that this myelination is from oligodendrocytes sparing, as neuroinflammation caused by the secondary injury has been shown to be incompatible with myelin sheath survival [35]. Indeed, increased expression of markers for oligodendrocyte progenitor cells were measured following cell therapy. IGF-1 was previously shown to promote oligodendrocyte differentiation and survival during normal development [12]. Interestingly, we found that myelin integrity was better preserved and complete functional loss was significantly reduced in mice treated with BMMSC-IGF1. This was associated with increased functional recovery in the BMMSCIGF1-treated group.

Despite the positive gains that we and others have observed with IGF-1, this cytokine has been reported to participate in tumor formation. If the overexpression of IGF-1 in cell therapy was used clinically, the longevity of this expression could be controlled by the introduction of a suicide gene [36], allowing the elimination of these cells in a desired time, after their usefulness has expired. Though we did not observe any tumor formation with BMMSC-IGF1 treatment,

Table 1 Morphological analysis of the spinal cord of mice 4 weeks after injury

\begin{tabular}{|c|c|c|c|c|c|c|c|c|c|}
\hline & Saline\#1 & Saline\#2 & Saline\#3 & BMMSC\#1 & BMMSC\#2 & BMMSC\#3 & $\begin{array}{l}\text { BMMSC- } \\
\text { IGF1\#1 }\end{array}$ & $\begin{array}{l}\text { BMMSC- } \\
\text { IGF1\#2 }\end{array}$ & $\begin{array}{l}\text { BMMSC- } \\
\text { IGF1\#3 }\end{array}$ \\
\hline Collagen fibers & †十 & †十† & $\dagger$ & t & $\dagger$ & $\dagger$ & $\dagger$ & - & $\dagger$ \\
\hline No. of images & $5 / 10$ & $10 / 10$ & $2 / 10$ & $3 / 10$ & $2 / 10$ & $1 / 10$ & $7 / 10$ & $0 / 10$ & $1 / 10$ \\
\hline $\begin{array}{l}\text { Thickness of } \\
\text { the fibers }\end{array}$ & Thick & Thick & Thin & Thin & Thin & Thin & Thin & - & Thick \\
\hline Myelin sheath & $\dagger$ & - & †十 & †十† & ††† & †十 & †十+ & †十+ & ††† \\
\hline No. of images & $10 / 10$ & $0 / 10$ & $10 / 10$ & $8 / 10$ & $10 / 10$ & $10 / 10$ & $9 / 10$ & $10 / 10$ & $9 / 10$ \\
\hline Profile & Demyelinated & - & Demyelinated & Myelinated & Myelinated & Myelinated & Myelinated & Myelinated & Myelinated \\
\hline Degeneration vacuoles & t† & ††† & ††† & ††† & - & $\dagger$ & $\dagger$ & - & ††† \\
\hline No. of images & $2 / 10$ & $9 / 10$ & $1 / 10$ & $3 / 10$ & $0 / 10$ & $6 / 10$ & $3 / 10$ & $0 / 10$ & $1 / 10$ \\
\hline
\end{tabular}

$\dagger=$ little, $\uparrow \dagger=$ reasonable, $+\uparrow \dagger=$ very 

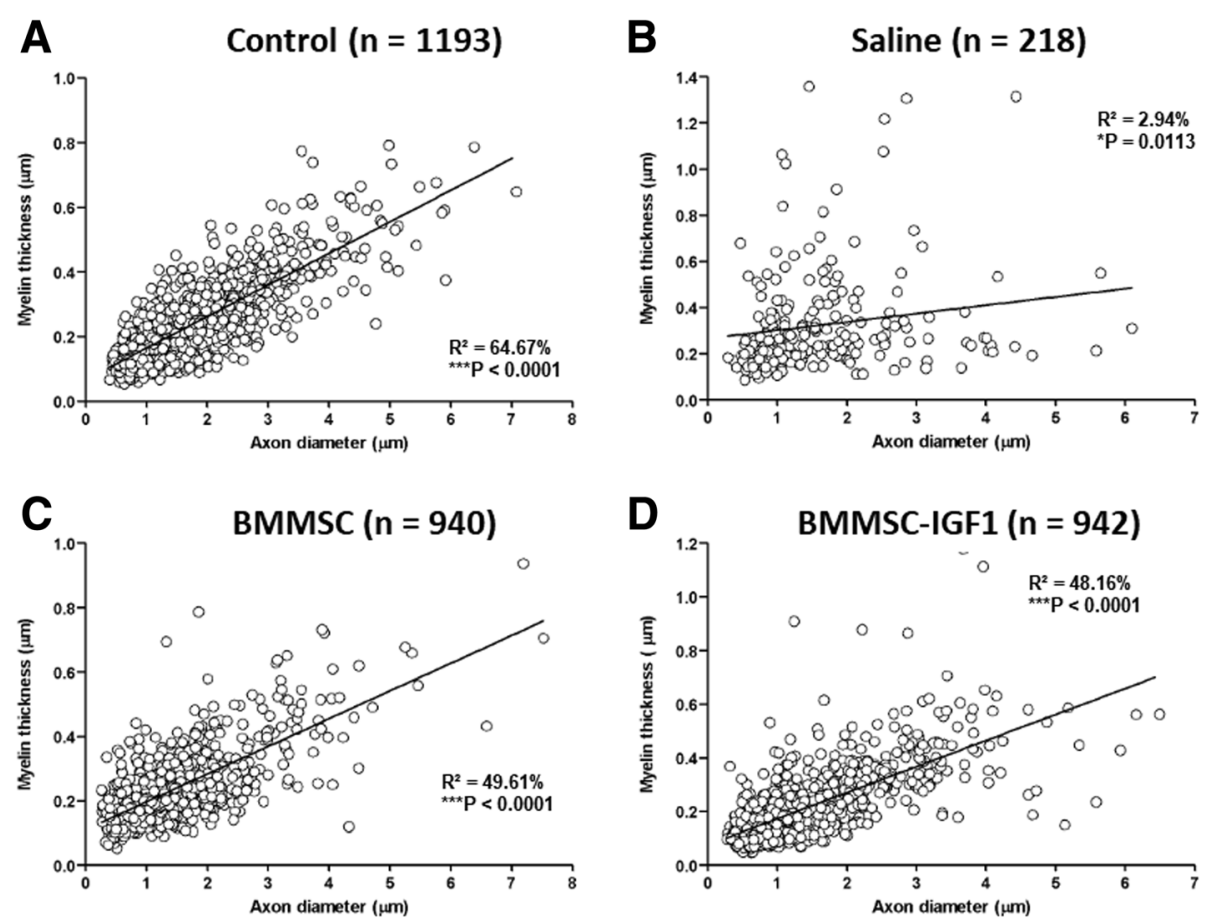

E

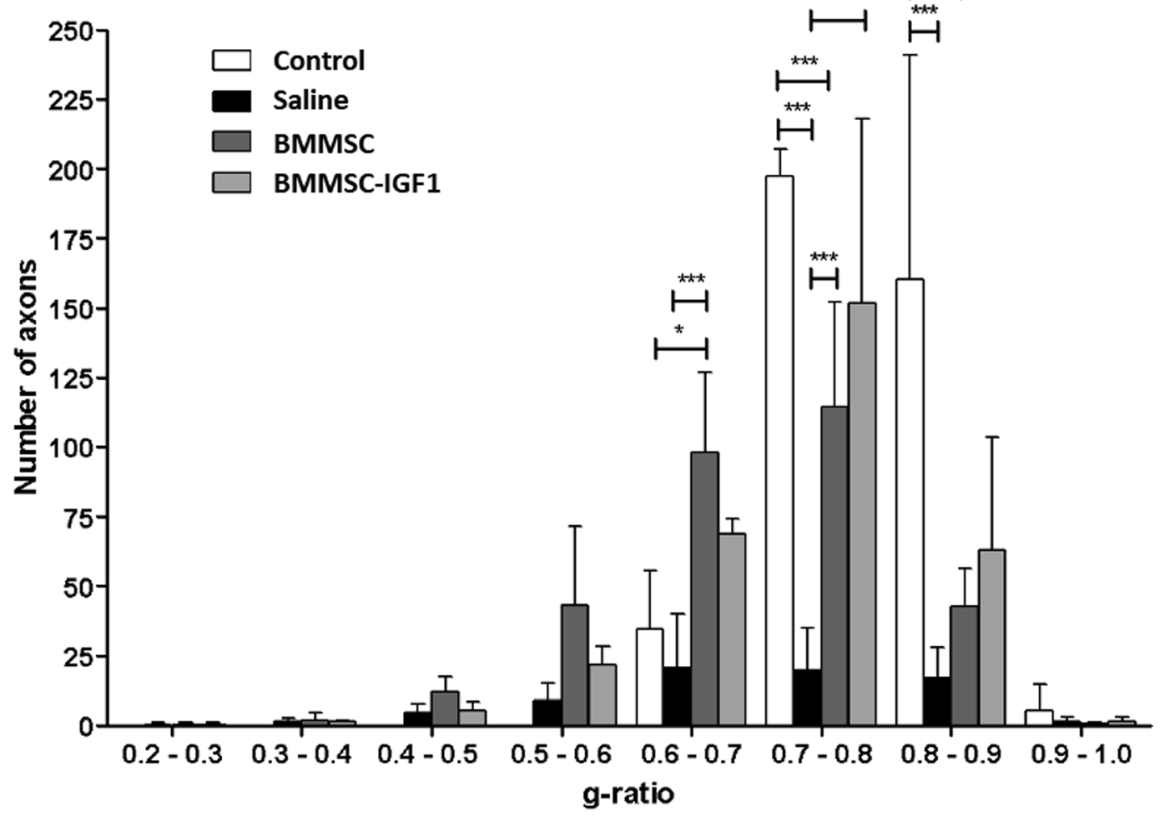

Fig. 8 Quantitative ultrastructural analyses of spinal cord sections in uninjured and SCI mice. a-d Linear regression analysis between myelin thickness and axon diameter from control, saline, BMMSC, and BMMSC-IGF1 groups. Three animals were used in each group. e Axon distribution by g-ratio range in control $(N=1193)$, saline $(N=218)$, BMMSC $(940)$, and BMMSC-IGF1 (942) groups. Analysis was done as described in the "Materials and methods" section. Values represent the mean \pm SEM in each range. ${ }^{*} P<0.05$; ${ }^{* * *} P<0.001$

in order to avert potentially risky clinical developments, additional studies investigating this and additional growth factors that are not linked with tumor formation should be further explored.

\section{Conclusion}

The association of BMMSCs and IGF-1 is beneficial for the survival of transplanted cells following SCI, as well as for therapeutic effects, as shown by the modulation of 
the acute phase and secondary injury seen here, which was shown to have a great impact on the long-term functional gains. Finally, we speculate that BMMSC therapy, in combination with growth factors, like IGF-1, may improve the effectiveness of BMMSC mediating tissue regeneration in SCI.

\section{Additional files}

Additional file 1: Figure S1. Experimental design of the study. (TIFF 698 kb) Additional file 2: Figure S2. Still frame images of SCI mice in DigiGait system. Representative images of (A) uninjured, (B) saline (C) BMMSC, and (D) BMMSC-IGF1-treated mice during DigiGait evaluation. (TIFF 2504 kb)

\begin{abstract}
Abbreviations
BMMSC: Bone marrow-derived mesenchymal stem cells; BMS: Basso Mouse Scale; Casp3: Caspase-3; CNS: Central nervous system; DCX: Doublecortin; DMEM: Dulbecco's modified Eagle's medium; GFAP: Glial fibrillary acidic protein; GFP: Green fluorescent protein; Gpx3: Glutathione peroxidase 3; IBA1: Ionized calcium binding adaptor molecule 1; IGF-1: Insulin-like growth factor type 1; MBP: Myelin basic protein; MDA: Malondialdehyde; Nfe2L2: Nuclear factor erythroid 2-related factor 2; NOS2: Nitric oxide synthase 2; Olig1: Oligodendrocyte transcription factor 1;

Olig2: Oligodendrocyte transcription factor 2; PFA: Paraformaldehyde; RTqPCR: Quantitative reverse transcription polymerase chain reaction; SCl: Spinal cord injury; SDF-1: Stromal cell-derived factor
\end{abstract}

\section{Acknowledgements}

Not applicable.

\section{Funding}

Financial support was granted by the following Brazilian agencies: The National Bank for Economic and Social Development (BNDES), the National Research Council (CNPq), the Foundation of Support for Research of the State of Bahia (FAPESB) and Funding Authority for Studies and Projects (FINEP).

\section{Availability of data and materials}

The datasets used and/or analyzed during the current study are available from the corresponding author on reasonable request.

\section{Authors' contributions}

KJA contributed to the conception and design, financial support, collection and/or assembly of data, data analysis and interpretation, manuscript writing, and the final approval of the manuscript. TAdS contributed to the collection and/or assembly of data, data analysis, and interpretation. GCS contributed to the collection and/or assembly of data. CMA contributed to the collection and/or assembly of data, and data analysis and interpretation. RAM contributed to the collection and/or assembly of data. CKN contributed to the collection and/or assembly of data, and data analysis and interpretation. DNS contributed to the collection and/or assembly of data, and data analysis and interpretation. CXRV contributed to the collection and/or assembly of data, and data analysis and interpretation. CPF contributed to the collection and/or assembly of data. WLCdS contributed to the data analysis and interpretation. RFdES contributed to the collection and/or assembly of data. AFE contributed to the data analysis and interpretation. CFV contributed to the conception and design. RRdS contributed to the conception and design and financial support. BSdFS contributed to the conception and design, data analysis and interpretation, manuscript writing, and the final approval of the manuscript. MBPS contributed to the conception and design, data analysis and interpretation, manuscript writing, and the final approval of the manuscript. All authors read and approved the final manuscript.

\section{Ethics approval and consent to participate}

This study was approved by the local ethics committee for animal use at the Hospital São Rafael (CEUA-HSR).
Consent for publication

Not applicable

\section{Competing interests}

The authors declare that they have no competing interests.

\section{Publisher's Note}

Springer Nature remains neutral with regard to jurisdictional claims in published maps and institutional affiliations.

\section{Author details}

${ }^{1}$ Center for Biotechnology and Cell Therapy, Hospital São Rafael, Salvador, BA, Brazil. ${ }^{2}$ Gonçalo Moniz Institute, FIOCRUZ, Rua Waldemar Falcão, 121, Candeal, Salvador, Bahia 40296-710, Brazil. ${ }^{3}$ Federal University of Bahia, UFBA, Salvador, BA, Brazil. ${ }^{4}$ National Institute of Science and Technology for Regenerative Medicine, Rio de Janeiro, RJ, Brazil. ${ }^{5}$ São Rafael Hospital, D'Or Institute for Research and Education (IDOR), Salvador, Brazil.

Received: 14 November 2018 Revised: 19 February 2019

Accepted: 26 March 2019 Published online: 21 May 2019

\section{References}

1. McDonald JW, Sadowsky C. Spinal-cord injury. Lancet. 2002;359:417-25.

2. Ribeiro TB, Duarte AS, Longhini AL, et al. Neuroprotection and immunomodulation by xenografted human mesenchymal stem cells following spinal cord ventral root avulsion. Sci Rep. 2015;5:16167.

3. Shende P, Subedi M. Pathophysiology, mechanisms and applications of mesenchymal stem cells for the treatment of spinal cord injury. Biomed Pharmacother. 2017;91:693-706.

4. Qu J, Zhang H. Roles of mesenchymal stem cells in spinal cord injury. Stem Cells Int. 2017;10:1155

5. Moya A, Paquet J, Deschepper M, Larochette N, Oudina K, Denoeud C, Bensidhoum $\mathrm{M}$, et al. Mesenchymal stem cell failure to adapt to glucose shortage and rapidly use intracellular energy reserves through glycolysis explains poor cell survival after implantation. Stem Cells. 2018;36(3):363-76.

6. Zachar L, Bačenková D, Rosocha J. Activation, homing, and role of the mesenchymal stem cells in the inflammatory environment. J Inflamm Res. 2016:9:231-40

7. Awad Bl, Carmody MA, Steinmetz MP. Potential role of growth factors in the management of spinal cord injury. World Neurosurg. 2015:83(1):120-31.

8. Novikova LN, Brohlin M, Kingham PJ, Novikov LN, Wiberg M. Neuroprotective and growth-promoting effects of bone marrow stromal cells after cervical spinal cord injury in adult rats. Cytotherapy. 2011;13(7): 873-87.

9. Gonçalves GVM, Silva DN, Carvalho RH, Souza BSF, Silva KN, Vasconcelos JF, et al. Generation and characterization of transgenic mouse mesenchymal stem cell lines expressing hIGF-1 or hG-CSF. Cytotechnology. 2017;70(2): 577-91.

10. Shi Y, Su J, Roberts Al, Shou P, Rabson AB, Ren G. How mesenchymal stem cells interact with tissue immune responses. Trends Immunol. 2012;33(3): 136-43.

11. Garofalo RS, Rosen OM. Insulin and insulin-like growth factor 1 (IGF-1) receptors during central nervous system development: expression of two immunologically distinct IGF-1 receptor beta subunits. Mol Cell Biol. 1989. 9(7):2806-17.

12. Dyer AH, Vahdatpour C, Sanfeliu A, Tropea D. The role of insulin-like growth factor 1 (IGF-1) in brain development, maturation and neuroplasticity. Neuroscience. 2016:325:89-99.

13. Hsieh J, Aimone JB, Kaspar BK, Kuwabara T, Nakashima K, Gage FH. IGF-I instructs multipotent adult neural progenitor cells to become oligodendrocytes. J Cell Biol. 2004;164(1):111-22

14. Ye P, Carson J, D'Ercole AJ. In vivo actions of insulin-like growth factor-I (IGF-I) on brain myelination: studies of IGF-I and IGF binding protein-1 (IGFBP-1) transgenic mice. J Neurosci. 1995;15(11):7344-56.

15. Da D, Torres-aleman I, Dávila D, Torres-aleman I. Neuronal death by oxidative stress involves activation of $\mathrm{FOXO} 3$ through a two-arm pathway that activates stress kinases and attenuates insulin-like growth factor signaling. Mol Biol Cell. 2008;19(5):2014-25.

16. Duarte Al, Santos P, Oliveira CR, Santos MS, Rego AC. Insulin neuroprotection against oxidative stress is mediated by Akt and GSK-3 $\beta$ 
signaling pathways and changes in protein expression. Biochim Biophys Acta - Mol Cell Res. 2008;1783(6):994-1002.

17. Tiwari SK, Manoj G, Sharma V, et al. Relevance of Helicobacter pylori genotypes in gastric pathology and its association with plasma malondialdehyde and nitric oxide levels. Inflammopharmacology. 2010; 18(2):59-64.

18. Schmittgen TD, Livak KJ. Analyzing real-time PCR data by the comparative C(T) method. Nat Protoc. 2008;3(6):1101-8.

19. Basso DM, Fisher LC, Anderson AJ, Jakeman LB, MCTique DM, Popovich PG. Basso Mouse Scale for locomotion detects differences in recovery after spinal cord injury in five common mouse strains. J Neurotrauma. 2006;23(5):635-59.

20. Madathil SK, Evans HN, Saatman KE. Temporal and regional changes in IGF1/IGF-1R signaling in the mouse brain after traumatic brain injury. J Neurotrauma. 2010;2(1):95-107.

21. Choi YS, Cho HY, Hoyt KR, Naegele JR, Obrietan K. IGF-1 receptor-mediated ERK/MAPK signaling couples status epilepticus to progenitor cell proliferation in the subgranular layer of the dentate gyrus. Glia. 2008;56(7):791-800.

22. Kong X, Gao J. Macrophage polarization: a key event in the secondary phase of acute spinal cord injury. J Cell Mol Med. 2017;21(5):941-54.

23. Eggenhofer E, Luk F, Dahlke MH, Hoogduijn MJ. The life and fate of mesenchymal stem cells. Front Immunol. 2014;5:148.

24. Saeki M, Maeda S, Wada K, Kamisaki Y. Insulin-like growth factor-1 protects peroxynitrite-induced cell death by preventing cytochrome $c$-induced caspase-3 activation. J Cell Biochem. 2002;84(4):708-16.

25. Huat TJ, Khan AA, Pati S, Mustafa Z, Abdullah JM, Jaafar H. IGF-1 enhances cell proliferation and survival during early differentiation of mesenchymal stem cells to neural progenitor-like cells. BMC Neurosci. 2014;15:91.

26. Youssef A, Aboalola D, Han VKM. The roles of insulin-like growth factors in mesenchymal stem cell niche. Stem Cells Int. 2017:94533108. https://doi. org/10.1155/2017/9453108.

27. Zhao B, Zheng Z. Insulin growth factor 1 protects neural stem cells against apoptosis induced by hypoxia through Akt/mitogen-activated protein kinase/extracellular signal-regulated kinase (Akt/MAPK/ERK) pathway in hypoxia-ishchemic encephalopathy. Med Sci Monit. 2017;23:1872-9.

28. Aloisi F. Immune function of microglia. Glia. 2001;36(2):165-79.

29. Ekdahl $C T$, Kokaia $Z$, Lindvall O. Brain inflammation and adult neurogenesis: the dual role of microglia. Neuroscience. 2009;158(3):1021-9.

30. Aberg D. Role of the growth hormone/insulin-like growth factor 1 axis in neurogenesis. Endocr Dev. 2010:17:63-76.

31. Zhou Z, Peng X, Insolera R, Fink DJ, Mata M. IL-10 promotes neuronal survival following spinal cord injury. Exp Neurol. 2009;220(1):183-90.

32. Ho S-Y, Ling T-Y, Lin H-Y, et al. SDF-1/CXCR4 signaling maintains stemness signature in mouse neural stem/progenitor cells. Stem Cells Int. 2017:2493752. https://doi.org/10.1155/2017/2493752.

33. Yan YP, Sailor KA, Vemuganti R, Dempsey RJ. Insulin-like growth factor-1 is an endogenous mediator of focal ischemia-induced neural progenitor proliferation. Eur J Neurosci. 2006;24(1):45-54.

34. Peferoen L, Kipp M, van der Valk P, van Noort JM, Amor S. Oligodendrocytemicroglia cross-talk in the central nervous system. Immunology. 2014;39(6):443-59.

35. Chomiak T, Hu B. What is the optimal value of the g-ratio for myelinated fibers in the rat CNS? A theoretical approach. PLoS One. 2009;4(11):e7754.

36. Kalimuthu S, Oh JM, Gangadaran P, et al. Genetically engineered suicide gene in mesenchymal stem cells using a Tet-On system for anaplastic thyroid cancer. Gelovani JG, ed. PLoS One. 2017;12(7):e0181318.

\section{Ready to submit your research? Choose BMC and benefit from:}

- fast, convenient online submission

- thorough peer review by experienced researchers in your field

- rapid publication on acceptance

- support for research data, including large and complex data types

- gold Open Access which fosters wider collaboration and increased citations

- maximum visibility for your research: over $100 \mathrm{M}$ website views per year

At $\mathrm{BMC}$, research is always in progress.

Learn more biomedcentral.com/submissions 